\title{
University Students' Beliefs and Attitudes Regarding Foreign Language Learning in France
}

\author{
Nathalie Piquemal and Robert Renaud
}

This study is based on a survey of 1,305 university students enrolled in English and other foreign-language classes across year levels in four major universities in France. It explores the factors that promote or hinder multilingualism, with special attention to the following questions: What are the beliefs and attitudes of students enrolled in various postsecondary institutions across France toward learning a foreign language? How do these beliefs and attitudes change as students progress from beginning first-year students to upper years? The results suggest that the reasons first-year students typically have for studying a foreign language have more to do with internal factors (e.g., personal attitude) than with external factoars (e.g., social value). Moreover, this trend becomes more pronounced with upper-year students whose motivation to learn a foreign language compared with that of first-year students is influenced less by perceived societal beliefs and more by intrinsic reasons.

Ce projet de recherche repose sur un sondage auprès de 1305 étudiants inscrits à des cours d'ALE ou d'autres langues étrangères de divers niveaux dans quatre grandes universités en France. Il porte sur les facteurs qui favorisent ou entravent le multilinguisme et cherche à répondre aux questions suivantes: Quelles croyances et attitudes les étudiants inscrits à diverses institutions universitaires en France entretiennent-ils face à l'apprentissage d'une langue étrangère? Dans quelle mesure ces croyances et attitudes changent-elles à mesure que les étudiants passent des cours de première année à des cours plus avancés? Les résultats indiquent que les raisons qui poussent les étudiants en première année à étudier une langue étrangère sont typiquement davantage liées à des facteurs internes ( $p$. ex. attitude individuelle) qu'externes ( $p$. ex. valeur sociale). De plus, cette tendance s'accentue chez les étudiants plus avancés, dont la motivation à apprendre une langue étrangère est encore moins influencée par des croyances sociales et plus par des raisons intrinsèques.

\section{Introduction}

Although the idea that the learner's beliefs about and attitudes toward foreign language learning are key in facilitating or hindering success is not new, little research explores these beliefs and attitudes in relation to broader 
social contexts of foreign language learning in varying institutions, and with a large sample of learners from various year levels. Indeed, with the exception of Rifkin's (2000) research in the United States, much of the research on foreign language learners' own personal beliefs has focused on beginning language classes from one institution, usually in the US, leaving out two important factors, namely, the perception of societal norms, also referred to as socio-suggestive norms (Miele, 1982) and the evolution of beliefs and attitudes across year levels. Furthermore, although the literature has addressed the need to link sociocultural factors with foreign language learning (Demmert, 1993; Miele; Pennycook, 1994; Strevens, 1978; Turner, 1974), much of the research to date has focused on case studies that highlight individual social circumstances in foreign language learning and mainly in classroom contexts (Graham \& Brown, 1996; Martin, 1990; Norton \& Toohey, 2001).

Therefore, the purpose of the research reported in this article is to gain a better understanding of the factors that promote or hinder multilingualism, with special attention to learners' beliefs and attitudes toward foreign language learning, namely, English, as well as the effect of contextual influences or socio-suggestive norms, on foreign language learning in France. By sociosuggestive norms, we mean perceived factors such as the social value of foreign language learning, pedagogical practice, public attitudes, opportunities for multilinguals, and government initiatives. This study set out to answer two questions. First, what are the beliefs and attitudes that students enrolled in postsecondary institutions across France have toward learning English as a foreign language? Second, how do these beliefs and attitudes change as students progress from first-year students to upper years? More specifically, students' beliefs and attitudes were assessed in terms of the effect of social norms on foreign language learning (i.e., how much students think society values foreign language learning), perceived advantages of foreign language learning, the role of instruction in foreign language learning, personal attitudes toward foreign language learning, and personal experiences in foreign language learning. Central to this study is the recognition that students' motivation is inherently shaped by their beliefs and attitudes toward learning a foreign language (Gardner, 1985; Gardner \& Lambert, 1972).

This article reports the results of a survey of 1,305 university students enrolled in foreign language classes (English and at least one other foreign language) across three year levels in each of four universities located in varying geographical locations in France. The findings of this study support several implications that will help better inform teacher practice and policy development in France and in other countries where students exhibit similar beliefs and attitudes. 


\section{Review of the Literature and Conceptual Framework}

The idea that students' beliefs about and attitudes toward foreign language learning have an effect on their success or failure in achieving competence in a foreign language is well documented (Horwitz, 1988; Jernigan, 2001; Kern, 1995; Miele, 1982; Rifkin, 2000; Strevens, 1978). One focus of research exploring students' beliefs about and attitudes toward foreign language learning contends that individuals' positive or negative beliefs and perceptions about foreign language learning have a similarly positive or negative effect on their success. Mantle-Bromley (1995), for example, argues that positive beliefs about foreign language learning combined with a positive learning environment such as trust-building between teacher and student facilitate foreign language learning and that negative beliefs hinder success. Horwitz argues that students' beliefs about foreign language learning affect the learning strategies that these students choose and contends that teachers cannot afford to ignore their students' beliefs if they wish to implement teaching methods that are efficient and well received. Jernigan explored the role that students' beliefs about foreign language learning play in their decisions to continue or discontinue their studies and found that teachers plan discussions with their students around these beliefs. MacIntyre and Gardner (1994) argue that language anxiety related to issues of pronunciation has a negative effect on foreign language learning. Similarly, Horwitz (1991) argues that anxiety influences the communication strategies used by foreign language learners. In a different yet related way, Kamhi-Stein (2003) used four case studies and found that students' beliefs about both their heritage language (as valuable or not) and reading in English and in Spanish affected their reading behavior. This shows that students' beliefs about the social value of their heritage language are likely to affect student learning. Therefore, this article focuses on examining students' perceived social value of learning a foreign language such as English and the extent to which such perception is embedded in students' motivation.

More closely related to our research focus on external and internal motivation, Gardner's (1985) and Gardner and Lambert's (1972) socio-educational model of integrative/instrumental motivation provides valuable insights into the role that attitudes, motivation, and orientations play in second-language achievement. They identified two kinds of orientations: integrative orientation, which refers to a desire to learn a second language in order to identify with the language community; and instrumental orientation, which refers to practical reasons for learning a second language such as career or course credit. Their findings showed that second-language achievement was positively related to instrumental motivation and even more strongly related to integrative motivation (also see Masgoret \& Gardner, 2003). 
Our study identifies similar factors, including perceived opportunities, personal attitudes, and experiences toward foreign language learning while offering additional insights into the perceived social value of foreign language learning. This includes not only students' perceptions on foreign language learning as socially and culturally bound (Dörnyei, 2003) or students' desire to learn a foreign language because of a desire to be accepted by the new linguistic community (Gardner, 1985), but also, and perhaps more important, the extent to which students believe that the society in which they live values foreign language learning.

Sociolinguistic theories have been developed to explain the social nature of learning as it applies to learning a foreign language. Gumperz and Hymes (1972) stressed the role of cultural beliefs in learning to speak, which is essentially a reflection of the continual interplay between linguistic structure and its sociocultural context. In particular, Hymes' (1972) work on the notion of the ethnography of speaking stresses the importance of looking at the cultural organization of language use in order to understand shared speaking practices and shared conceptions about the role of language in any given culture. Therefore, fundamental to the sociolinguistic view that language is used in relation to a specific social and cultural context (Hymes) and that learning is shaped by sociocultural participation in a given community (Rogoff, 1994) is the assumption that many of the characteristics of foreign language learning are dependent not only on teaching methods and learning strategies, but also on sociocultural influences. This view is also echoed by Norton and Toohey (2001), who argue that approaches leading to a better understanding of what promotes foreign language learning should "focus not only on learners' internal characteristics, learning strategies, or linguistic outputs but also on the reception of their actions in particular sociocultural communities" (p. 308).

Another perspective that attempts to explain the effects of social-suggestive norms in foreign language learning is the influence of community and second-language teaching as developed by Ashworth (1985). Ashworth explored how varying communities (geopolitical (neighborhoods), common interests (family, speech community), and professional (educational institutions) affect learners' attitudes, expectations, and aspirations toward foreign language learning. In particular, Ashworth explained that socioeconomic status affects students' attitudes toward foreign language learning, which is key in determining who attends language classes and how well the students do. Ashworth suggests that teachers need to be responsive to inequities among foreign language learners by encouraging special programs and giving a more influential role to local neighborhoods. Moreover, Ashworth also explored how national policies (immigration, education, language rights, economic and employment policies) affect foreign language teaching and learning (what languages are prioritized, who will teach what language 
to whom, how well the students will do). In sum, Ashworth suggests that in order to better benefit students, language teachers need to "develop a political awareness and sensitivity" (p. 103) to the philosophies that underlie national policies and to emerging socioeconomic trends in communities, with special attention to the unmet needs of individuals.

In keeping with Rifkin (2000), who contends that "in order to develop plans to overcome learners' counterproductive beliefs about foreign language learning, we must first understand exactly what those beliefs are" (pp. 394-395), our study recognizes a need to explore specific beliefs about foreign language learning in order to better inform pedagogical practices, government policies, and program development. If teachers and researchers are more cognizant of students' beliefs and attitudes toward foreign language learning, they might be in a better position to foster learning strategies that address (and challenge when necessary) these beliefs. Similarly, if policymakers are sensitized to the social, cultural, and historical factors that influence these beliefs, they might be in a better position to define educational goals by using these factors as a reference point for policy development.

As the global economy continues to develop, so too does the need for countries to prepare themselves such that they can better participate on an international level. One factor that seems to play a sizeable role in how well a country can continue to flourish in the 21st century is the ability of its population to learn the language(s) necessary for efficient communication with other nations. Recently, France has begun to recognize the need to promote multilingualism in the context of globalization. Previous French Minister of Education Jack Lang (2001) acknowledged that France cannot participate in the new economy through the medium of English or French only: "Tout montre que l'avenir de notre pays et des jeunes Européens impose la maîtrise d'au moins deux langues vivantes étrangères en plus de la langue maternelle" (p. 10), which translates as "Everything shows that the future of our country and of European Youth requires mastering at least two foreign languages besides the heritage language" (authors' translation). In such a framework, France has attempted to introduce foreign language teaching in primary classrooms (mainly English), besides the current mandatory study of two foreign languages in both junior and senior high school (one of which is generally English). Such an initiative responds to the growing concern for international participation as well as to the growing recognition of English as an international language. This type of initiative challenges, although not necessarily successfully, French language ideology around the societal belief that French, as an "almost recognized international language" and as a "national unifier" against regional languages, needs to be preserved and defended against the dominance of English, as well as against France's minority regional languages (Kasuya, 2001). Therefore, when ex- 
ploring the beliefs and attitudes of foreign language learners in France, one needs to keep in mind some of the societal complexities, a significant one of which being that although English undoubtedly has a privileged position among foreign languages in France, it nonetheless faces an undeniable degree of defensiveness from those who believe that the French language is to be vigorously defended against the perceived global dominance of English (Kasuya, 2001; Calvet, 1999; Hagège, 1996).

\section{Method}

\section{Participants}

The participants were 1,305 university students enrolled in English language classes, ranging from 15 to over 200 students and studying at least one other foreign language such as Spanish, Italian, German, Japanese, Arabic, or Russian from four geographical locations in France: Université Paris IV, Université de Provence à Aix-en-Provence, Université de Perpignan, and Université du Var à Toulon. These universities were chosen because they are all located in large urban centers to which the researcher was granted access, and each offers language programs at all university year levels and in two main areas of study. The year levels covered in this study include first year ( $n=649)$, second (DEUG) $(n=343)$, and third (Licence) year $(n=313$, equivalent to undergraduate in North America). Areas of study included LLCE (Lettres, Langues, et Cultures Etrangères) and LEA (Langues Etrangères Appliquées). The former field of study focuses mainly on literature, civilization, and history, whereas the latter focuses on more marketable fields such as economics, business administration, and law. All students enrolled in English classes at all three year levels were surveyed during the second semester (January-June) 2003. The approximate rate of response was $40 \%$ for first- and second-year students and $50 \%$ for third-year students.

All the students surveyed had studied English and at least one other foreign language before arriving at the university. These students studied English as well as a second (and sometimes a third) foreign language for between five and seven years before entering their university program. Students in France are required to select a first foreign language at the beginning of their junior high school program and a second half-way through. Students continue studying these languages until the end of their high school program, with the option of selecting a third foreign language at the beginning of their high school program. Studying at least two foreign languages in both junior and high school is mandatory in France. There is no selection process for university entrance. The high school diploma (Baccalauréat) is all that is required to enter a university program. Although first-year university students are not beginners in foreign language learning, their levels of language 
proficiency vary greatly; by contrast, they are beginners in the field in which they have chosen to specialize (in this case either LLCE or LEA).

\section{Survey Instrument}

The survey instrument was developed in two stages (the survey was constructed by two researchers involved in an international study that involved three countries: Canada, France, and Japan). The first stage consisted of adapting items from existing instruments such as the Belief Inventory developed by Horwitz (BALLI, 1988), and the Strategy Inventory for Language Learning (SILL, Oxford, 1990). Additional questions were developed from individual interviews and focus group discussions in both Canada and in France. The final version contains 69 selected-response and six open-ended questions pertaining directly to students' beliefs and attitudes, 10 questions on demographics, four questions about the student's experience in learning a foreign language, and a general question that allows for any further response. The selected-response questions, which were the focus of the analysis in this study, were intended to assess the following factors: perceived social norms in foreign language learning, perceived advantages of foreign language learning, the role of instruction and instructional strategies in foreign language learning, personal beliefs and attitudes toward foreign language learning, and personal experiences in foreign language learning. Each question was answered using a 6-point Likert scale (from 1=strongly disagree to $6=$ strongly disagree) along with the option to answer "I do not wish to answer" or "I have no opinion." The questions aim at exploring both beliefs and attitudes, two factors that may help us better understand where language educators and policymakers should direct their efforts in order to facilitate success foreign language learning. For example, the statement "I respect people who speak more than one language" reflects an attitude that suggests a favorable evaluation of bilingualism, whereas the statement "Knowing a foreign language makes it easier to learn other subjects (such as sciences, mathematics, social studies, geography)" reflects a belief that there is a relationship between learning a foreign language and learning other subjects.

\section{Procedure}

After obtaining permission from deans and department heads, the first author approached professors individually to inform them about the research and to obtain their permission to distribute the surveys to the students. As the surveys were distributed at the beginning of the class, students were assured that (a) their participation was completely optional, (b) their responses would be kept confidential, and (c) whether they chose to participate had no effect on their course grade. Students were asked to complete 
the survey outside class time and to return their completed surveys to either a designated mailbox or their professor.

\section{Results}

To determine what latent constructs and their respective indicator items would be used to compare the latent mean differences across year levels, all 69 items were subjected to a principal components analysis with Promax rotation. More specifically, the purpose of this exploratory analysis was to develop a more parsimonious model consisting of only those items that would best reflect their intended factors. For each year level, a consistent factor structure that reflected the five subscales in the Foreign Language Questionnaire was obtained. The three items that loaded most strongly on a particular factor in each year was retained for the analyses. Thus the initial version of the abbreviated scale consisted of three items in each of the same five subscales as in the original version, leaving a total of 15 items. Preliminary confirmatory factor analyses using AMOS (version 5) was used to establish a baseline model that was more replicable across each of the three year levels. This resulted in the removal of one item, leaving a total of 14 . The retained items and the factors they represent are listed in the Appendix. The means and standard deviations for each observed variable in each year are

Table 1

Observed Means and Standard Deviations for Observed Variables in the Social-Suggestive Norms in the Foreign Language Learning Questionnaire

\begin{tabular}{llll}
\hline Item and description & Year 1 $(n=649)$ & Year 2 $(n=343)$ & Year 3 (n=313) \\
\hline SV1 government policies & $3.69(1.41)$ & $3.37(1.42)$ & $3.51(1.41)$ \\
SV2 normal part of life & $3.59(1.36)$ & $3.33(1.37)$ & $3.30(1.33)$ \\
SV3 becoming more interested & $4.27(1.18)$ & $3.93(1.28)$ & $4.25(1.08)$ \\
PO1 more educational opportunities & $4.71(1.14)$ & $4.63(1.20)$ & $4.58(1.20)$ \\
PO2 job advertisements & $5.05(0.98)$ & $5.07(1.07)$ & $5.05(0.91)$ \\
PO3 necessary to get a good job & $4.63(1.23)$ & $4.72(1.30)$ & $4.57(1.23)$ \\
TC1 classes important - beginner & $5.18(0.92)$ & $5.31(0.86)$ & $5.24(0.92)$ \\
TC2 classes important - intermediate & $5.13(0.92)$ & $5.25(0.85)$ & $5.17(0.93)$ \\
TC3 classes important - advanced & $4.78(1.23)$ & $5.02(1.08)$ & $4.98(1.06)$ \\
PA1 interesting activity & $5.46(0.74)$ & $5.61(0.62)$ & $5.62(0.53)$ \\
PA2 learn language and culture & $5.27(0.81)$ & $5.37(0.81)$ & $5.41(0.63)$ \\
PA3 know the speakers better & $4.81(1.11)$ & $5.05(0.99)$ & $4.97(0.95)$ \\
PE1 talk to native speakers & $4.52(1.28)$ & $4.48(1.41)$ & $4.64(1.31)$ \\
PE2 read newspaper & $3.66(1.57)$ & $3.86(1.49)$ & $4.22(1.27)$ \\
\hline
\end{tabular}

Note. Standard deviations in parentheses; Full wording for each item is listed in the Appendix. 
listed in Table 1. Inspection of skewness and kurtosis for each variable revealed no significant departure from normality.

In looking at the students' beliefs and attitudes in each year, a couple of findings are noteworthy. From the mean values listed in Table 1, it appears that first-year students felt that the degree to which society values learning a foreign language was modest at best. For example, first-year students were only mildly convinced of the existence of government policies to encourage the French to learn foreign languages $(M=3.69, S D=1.41)$. Interestingly, students in second and third years perceived even less societal value attached to learning foreign languages. However, the large standard deviations of the students' responses on the social value items show quite a bit of variability, with some students perceiving strong societal influence, whereas others thought the opposite. In contrast to the generally perceived weaker influence of social values, first-year students appeared to be intrinsically motivated

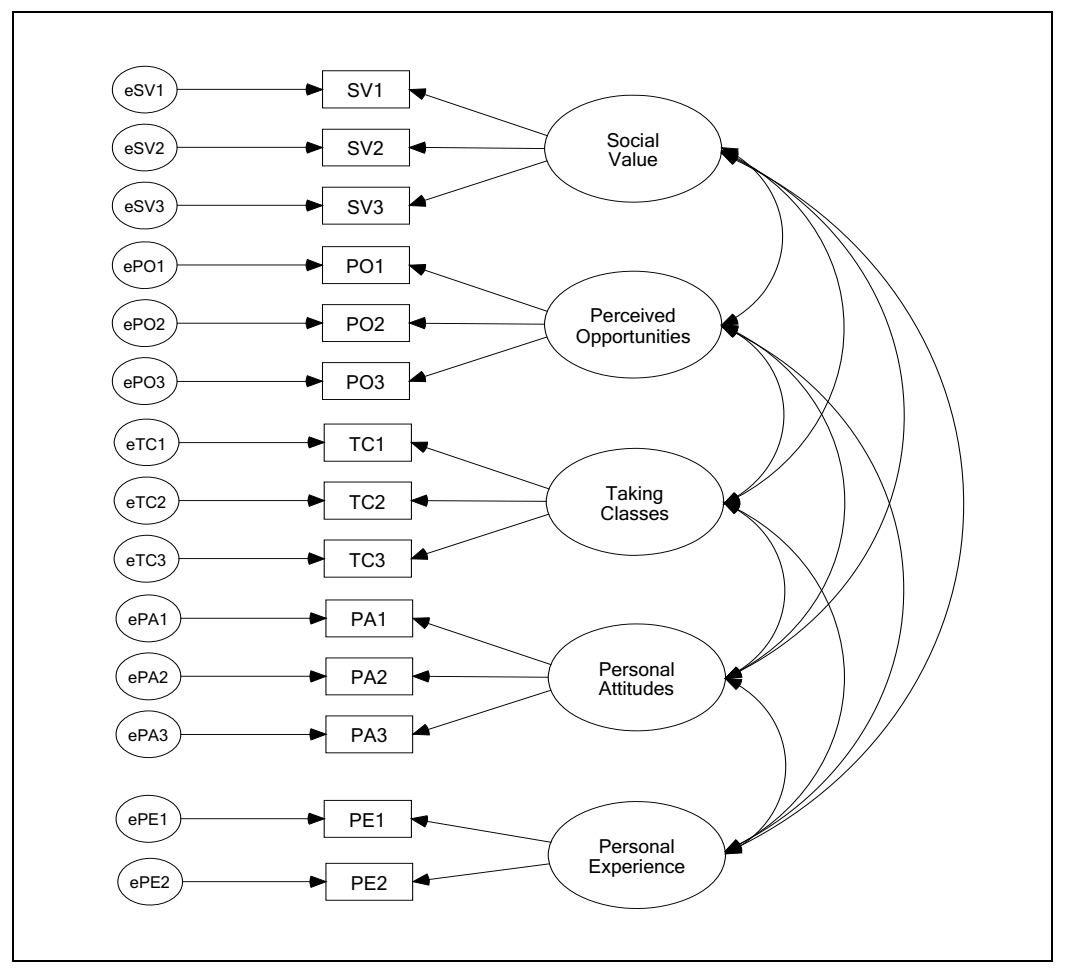

Figure 1. Baseline model depicting observed and latent variables representing beliefs and attitudes about foreign language learning. 
Table 2

Baseline Model Standardized Parameter Estimates for Beliefs and Attitudes About Foreign Language Learning (Year 1)

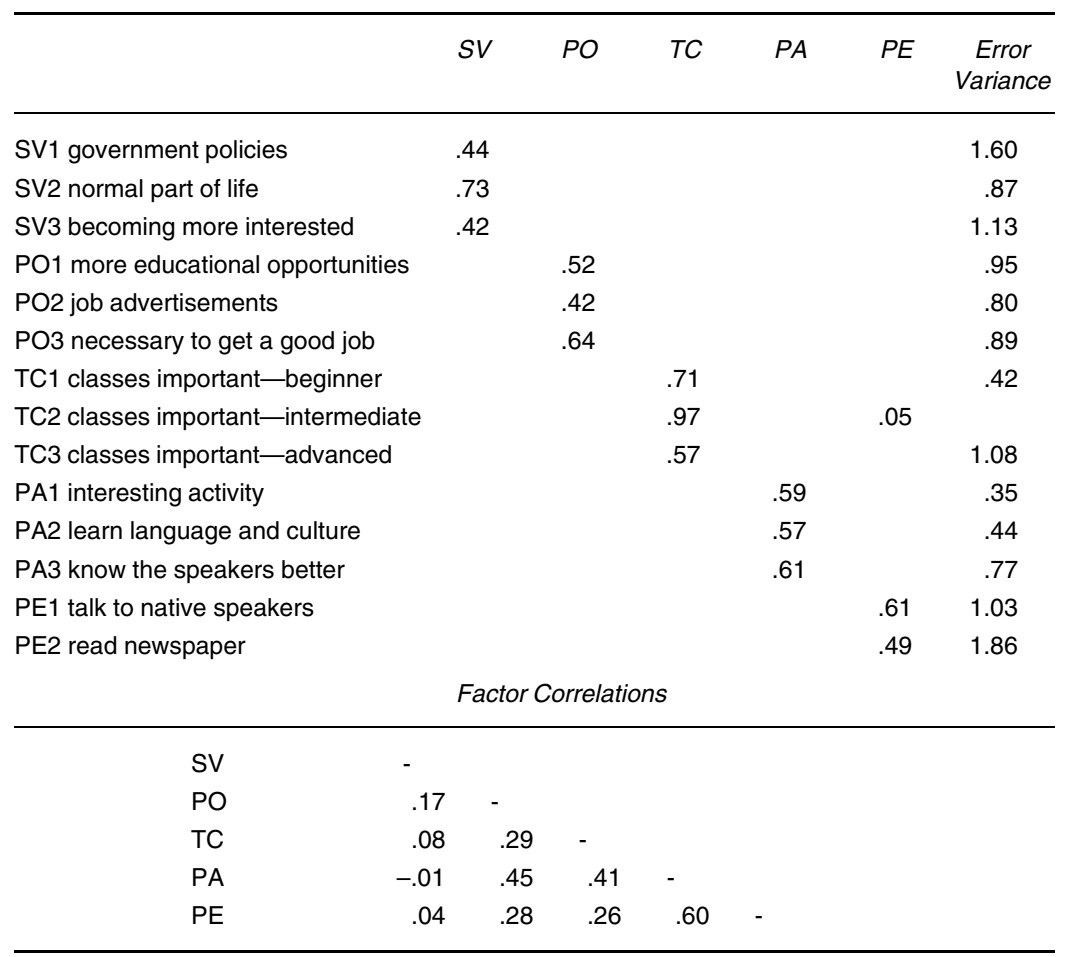

Note. SV=Social value; PO=Perceived Opportunities; TC=Taking Classes; PA=Personal Attitudes; PE=Personal

Experience;

toward learning a foreign language. Most first-year students tended to agree quite strongly that foreign language learning is an interesting activity $(M=5.46, S D=0.74)$.

Before conducting the between-group comparisons of latent means, a single baseline model was tested with each group. A visual representation of the baseline model is shown in Figure 1, which depicts the five latent variables, their representative observed variables (i.e., survey items), and the error component associated with each observed variable. Byrne (2001) provides a relatively nontechnical introduction to the logic and representation of structural equation models. Somewhat analogous to the concept of variance accounted for in correlation or regression, two commonly used 
Table 3

Baseline Model Standardized Parameter Estimates for Beliefs and Attitudes About Foreign Language Learning (Year 2)

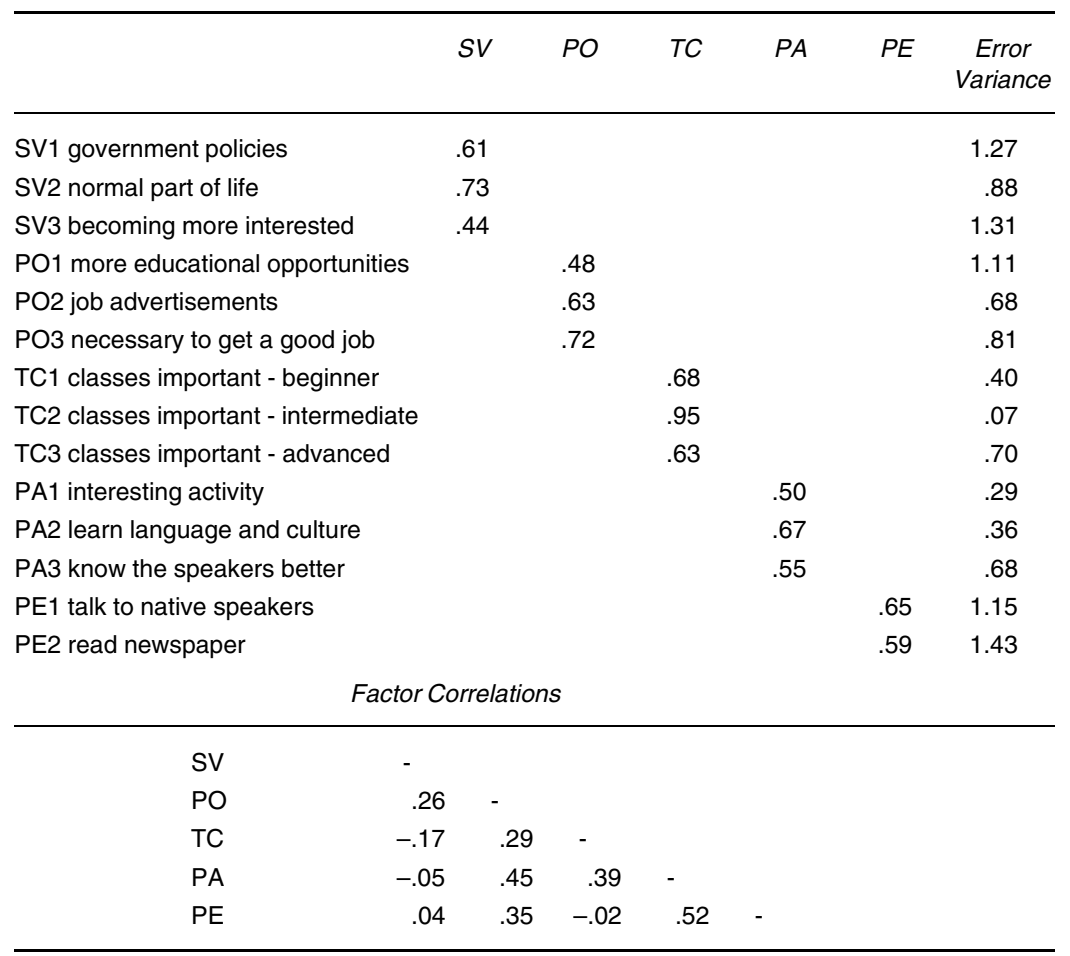

Note. SV=Social value; PO=Perceived Opportunities; TC=Taking Classes; PA=Personal Attitudes; PE=Personal Experience;

indices that indicate the degree of similarity between the actual data covariances and those of the estimated values based on the parameters in the model are the comparative fit index (CFI) and the root mean square error of approximation (RMSEA), with values of 1.0 and 0.0 respectively indicating a perfect fit between the model estimates and the actual data. In general, a model that yields a CFI value close to .95 and a RMSEA close to .05 represents an acceptable fit (Hu \& Bentler, 1999). The baseline model was found to fit the data fairly well in each group with Year 1 (CFI=.94, RMSEA=.04), Year 2 $(\mathrm{CFI}=.96$, RMSEA=.04), and Year $3(\mathrm{CFI}=.91$, RMSEA=.06). The baseline model standardized parameter estimates for Year 1, Year 2, and Year 3 are listed in Tables 2, 3, and 4 respectively. In each of the three year levels, the 
Table 4

Baseline Model Standardized Parameter Estimates for Beliefs and Attitudes About Foreign Language Learning (Year 3)

\begin{tabular}{|c|c|c|c|c|c|c|}
\hline & SV & $P O$ & $T C$ & $P A$ & $P E$ & $\begin{array}{c}\text { Error } \\
\text { Variance }\end{array}$ \\
\hline SV1 government policies & \multicolumn{2}{|l|}{.34} & & & & 1.76 \\
\hline SV2 normal part of life & \multicolumn{2}{|l|}{.83} & & & & .56 \\
\hline SV3 becoming more interested & \multicolumn{2}{|l|}{.43} & & & & .95 \\
\hline \multicolumn{2}{|l|}{ PO1 more educational opportunities } & .49 & & & & 1.09 \\
\hline \multicolumn{2}{|l|}{ PO2 job advertisements } & .68 & & & & .44 \\
\hline \multicolumn{2}{|l|}{ PO3 necessary to get a good job } & .71 & & & & .74 \\
\hline \multicolumn{2}{|l|}{ TC1 classes important - beginner } & & .72 & & & .41 \\
\hline \multicolumn{2}{|l|}{ TC2 classes important - intermediate } & & .95 & & & .09 \\
\hline \multicolumn{2}{|l|}{ TC3 classes important - advanced } & & .67 & & & .62 \\
\hline \multicolumn{2}{|l|}{ PA1 interesting activity } & & & .43 & & .23 \\
\hline \multicolumn{2}{|l|}{ PA2 learn language and culture } & & & .45 & & .32 \\
\hline \multicolumn{2}{|l|}{ PA3 know the speakers better } & & & .55 & & .63 \\
\hline PE1 talk to native speakers & & & & & .82 & .55 \\
\hline \multirow[t]{2}{*}{ PE2 read newspaper } & & & & & .51 & 1.19 \\
\hline & orrelatior & & & & & \\
\hline SV & & & & & & \\
\hline $\mathrm{PO}$ & - & & & & & \\
\hline-.06 & .15 & - & & & & \\
\hline PA & .08 & .26 & - & & & \\
\hline PE & .07 & -.04 & .46 & - & & \\
\hline
\end{tabular}

Note. SV=Social value; PO=Perceived Opportunities; TC=Taking Classes; PA=Personal Attitudes; PE=Personal

Experience;

error variances for some of the observed variables seem rather large (e.g., SV1, SV3, PE2) indicating that the amount of variance accounted for in each of these variables is relatively small compared with that of other observed variables such as TC2 and PA1. Although the variance accounted for by the observed variables could be improved by adding parameters to the baseline model, doing so would yield a more complex model that would not generalize across year levels as well as the current model.

Looking at Year 1 (Table 2), a few of the factors showed moderately strong correlations with one another. Personal Attitudes correlated with Perceived Opportunities, Taking Classes, and Personal Experience $(.45, .41$, and .60 respectively). This indicates that Year 1 students who are personally 
Table 5

Latent Variable Means Across Year Levels

\begin{tabular}{lccccc}
\hline & $S V$ & $P O$ & $T C$ & $P A$ & $P E$ \\
\hline Year 2 (compared against Year 1) & $-.21^{\star \star}$ & .02 & $.11^{\star}$ & .06 & \\
& $(.05)$ & $(.05)$ & $(.05)$ & $(.04)$ & $(.08)$ \\
Year 3 (compared against Year 2) & .06 & -.06 & -.06 & .00 & $.24^{\star \star}$ \\
& $(.05)$ & $(.06)$ & $(.06)$ & $(.05)$ & $(.09)$ \\
Year 3 (compared against Year 1) & $-.11^{\star \star}$ & -.05 & .05 & $.14^{\star *}$ & $.41^{\star \star}$ \\
& $(.04)$ & $(.05)$ & $(.05)$ & $(.03)$ & $(.09)$ \\
\hline
\end{tabular}

Note. SV=Social value; $\mathrm{PO}=$ Perceived Opportunities; $\mathrm{TC}=$ Taking Classes; $\mathrm{PA}=$ Personal Attitudes; $\mathrm{PE}=$ Personal

Experience; Standard Error in Parentheses; ${ }^{*} p<.05 ;{ }^{* *} p<.01$.

interested in learning a foreign language are also likely to value both in- and out-of-class learning that will help them take better advantage of later career opportunities. This pattern was again found with Year 2, as Personal Attitudes correlated with Perceived Opportunities, Taking Classes, and Personal Experiences $(.45, .39$, and .52 respectively). In Year 3, however, the factors appeared to become more independent, with the strongest relationship between only Personal Attitudes and Personal Experience (.46).

The procedure used in AMOS to compare latent variable means between groups (i.e., year levels) requires that the means of one group be fixed to 0 . Thus the values listed in Table 5 represent the differences between group means on each of the factors. Looking at the comparison between Year 1 and 2 with the mean values of Year 1 fixed to 0 , Year 2 students seemed to be less convinced that society in general values learning a foreign language ( $S V=$ $-.21)$. However, Year 2 students appeared to be more interested in learning a foreign language $(P A=.16)$ and more appreciative of the value of taking classes $(T C=.11)$. In comparing Year 2 and 3, Year 3 students reported having more personal experiences $(P E=.24)$. These differences were confirmed further in the comparisons between Year 1 and 3. Compared with Year 1, the perception of society's value of learning a foreign language was lower among Year 3 students $(S V=-.11)$. In addition, Year 3 students indicated that they had more personal interest $(P A=.14)$ and personal experience $(P E=.41)$ in learning a foreign language. In sum, the main finding that these results suggest is that many students appear to start learning a foreign language due more to internal reasons (e.g., personal interest) than external reasons (e.g., society thinks it is desirable or good). Looking at students in their second and third years of study, the influences of internal and external and reasons appear to be increasingly divergent, as upper-year students seem less concerned with how others might view studying a foreign language and more motivated by their own genuine interest. 


\section{Discussion}

The purpose of this study was to determine the types of beliefs and attitudes of university students in France regarding their learning of a foreign language. As well, these beliefs and attitudes were compared across year levels. Overall, the results of this study suggest that the reasons first-year students typically give for studying a foreign language have more to do with internal factors (e.g., personal attitude) than with external factors (e.g., social value). Moreover, this trend becomes more pronounced with upper-year students whose motivation to learn a foreign language, compared with first-year students, is influenced less by perceived societal beliefs and more by intrinsic reasons.

First-year university students are generally recent high-school graduates, recipients of the national high school degree, le Baccalauréat, which in France symbolizes a socially valued rite of passage. This degree is considered a social sine qua non by French society, especially given the Ministry of Education's goal in 1985 to increase the number of high-school graduates to $80 \%$. High-school students experience unquestionable pressure from friends, relatives, and the larger society to obtain this diploma. Once this degree is obtained, a significant pressure is off and new doors open. Students believe that this high-school degree will undoubtedly enable them to access postsecondary studies, particularly university studies. Indeed, in a recent article in a local newspaper, Beaud (2004, p. 18), a sociologist and researcher at the CNR (Centre National de Recherches Scientifiques), describes the Baccalauréat as a "passeport [qui] a toujours une fonction sociale fortement élevée ... [un] examen qui donne aussi des droits sociaux comme l'accès à l'enseignement supérieur et le statut envié d'étudiant.... C'est un visa pour le monde universitaire," which translates as "passport [that] still has a significantly high social value ... [an] exam that also provides social rights such as access to postsecondary education and to highly desired student status.... It is a visa for the university world" (authors' translation). At the end of high school, students may choose the area of study in which they wish to specialize. It is possible that armed with this degree, which carries important social value, first-year university students experience a great degree of enthusiasm largely due to external factors such as their own perceptions of how society values their degree and the pursuit of a postsecondary education. Given this general perception of how highly society values further education, it was interesting to find that this view was not as strong with respect to foreign language learning. In particular, first-year students thought that society viewed foreign language learning as only marginally important. Moreover, second- and third-year students judged the degree of societal value as lower than did their first-year cohorts. One possible explanation is that, as stated at the beginning of this article, France's collective consciousness appears to be 
somewhat conflicted when taking a stance on the importance of foreign languages. Indeed, although English is given a privileged position among foreign languages by the public, it tends to be simultaneously perceived as a threat to the French language given its increasing global dominance (Kasuya, 2001; Calvet, 1999; Hagège, 1996). Therefore, our young respondents may feel that the social value of foreign language learning is only marginally important because many French people may not have fully accepted the view that the French language has lost its competition with English for status as an international language. This perception might explain why university students who enroll in foreign language classes do so because of internal factors (personal attitudes and experiences) rather than because of external factors (social value). Another possible explanation is that most first-year students in this sample were between 18 and 19 years old and as such may not yet have developed a well-defined idea of what kind of profession they might target. This may be due in part to not yet being well aware of the supports and resources society can offer. As Beaud (2004) states, "il est très difficile lorsque l'on a dix-huit ans de savoir si l'on va aimer le droit, la sociologie ou la psychologie" (p. 18), which translates as "it is very difficult for an 18-year-old to know if he or she is going to like law, sociology, or psychology" (authors' translation).

As students progress in their second year of studies and then in their third year (license), it is anticipated that their academic maturity will develop further in at least two ways. First, one would expect that by the second or third year of university, students might begin to get a clearer sense of their own educational and professional purposes with a more grounded view of what might be available to them professionally. This study found that second- and third-year students reported more positive attitudes toward learning a foreign language compared with first-year students. Moreover, students in each year-level cohort consistently reported a moderate degree of perceived educational and career opportunities opening up as a result of foreign language study. Second, one could also hypothesize that university language classes have a significant effect on students' attitudes toward foreign language learning. Although first-year students in this study generally reported that taking classes was a fairly important part of learning a foreign language, this perceived importance was even higher among upperyear students. In other words, while taking these classes, students became more aware of the intrinsic value of the study of foreign languages such that learning a foreign language became an end in itself corresponding to a genuine interest in the specific discipline. The findings of this study clearly showed that these internal factors seemed to play a more dominant role in explaining student motivation. The perceived opportunities remained important, but they may be progressively associated with professions for which the study of foreign languages is an end rather than merely a tool; such 
professions could include teaching, interpreting, translating, and working abroad for the pleasure of being in an interlinguistic context or for the love of the foreign culture.

Although the findings of this study seem quite encouraging, one of the main design limitations is that this was a cross-sectional design. As such, one can only speculate as to how a particular group of first-year students might develop their beliefs and attitudes as they progress into later years. Not unlike students in many first-year programs, not all first-year students in these universities continue to the second year of their degree. Some fail and others drop out and choose another specialization or seek employment. It is possible that those who drop out were already more strongly influenced by the social value of learning a foreign language, whereas those students who progressed into the second and third year of their studies might have begun their programs with a strong personal interest. A second limitation was that some items in the survey were either too vague or did not correspond well to the response scale, which may have made it more difficult to assess students' perceptions accurately. For example, the three items representing the social value construct referred to "foreign languages" rather than any particular language. Students might have reported higher and more consistent agreement if these questions had referred to a particular and common language such as English. In contrast, other students' responses might have been based on relatively lesser-used languages (e.g., Ukrainian), perhaps leading to the view that there is little social value to learning foreign languages. Although the ratings of personal experiences were increasingly positive from first year to third year, the scale might have enabled students to respond more meaningfully if it had been based on a range of frequencies rather than levels of agreement.

The following questions need to be raised. Do students who drop out feel that the field of foreign language learning does not correspond to what they had imagined? Is the reason for dropping out due to an increasingly negative perception of the social value of learning foreign languages? Did they, for example, become increasingly persuaded that foreign language learning might not necessarily facilitate finding employment? Did they feel that the focus of the program was perhaps not congruent with how they hoped to use foreign languages in their professional and personal lives? Did they feel that the teaching strategies were not congruent with their desire to learn to communicate in the contemporary context of an increasingly globalized world? Many written comments that the students included in open-ended questions at the end of each section of the survey expressed a certain amount of disappointment due to the perceived lack of focus on communication and oral practice in their professors' teaching methods. As well, many of these written comments expressed a certain amount of dissatisfaction about the perceived lack of connection between the university's programs in foreign 
languages and contemporary needs for increasingly internationalized relationships. In contrast, although the results of this study do suggest that students who progress into the second and third year of their studies become increasingly interested in the study of languages themselves regardless of their potential employment value, one might ask what factors contribute most toward the development of this interest. How might teachers and policymakers better address the negative perceptions of these students as well as capitalize on the positive ones?

Our findings are congruent with Rifkin's (2000) study in that they show a relationship between beliefs and attitudes about foreign language learning and level of instruction. However, whereas Rifkin's study mainly focuses on individual learning strategies and learning styles, our study also takes into account respondents' perceptions of the social value of foreign language learning. Although many of the factors used in our survey differ from those used in Rifkin's study, a common finding between these two studies is that language instruction may have a significant effect on the evolution of students' beliefs and attitudes toward foreign language learning. In contrast to Horwitz's (1988) study on the Beliefs About Language Learning Inventory (BALLI) with a group of US students from the University of Texas, our findings show that French students have a significant level of both instrumental and integrative motivation, meaning that perhaps in contrast to American students from that particular university, students in France judge that their heritage language (French for the most part) is not sufficient in the context of an increasingly globalized world that is perceived to be dominated by English as an international language. This could also explain why in our survey results, the factor perceived opportunities received a consistently high rating. In the current context that positions English as an international language, perceived opportunities are likely to constitute a more important factor in non-English-speakers' decision to learn foreign languages (one of which in France is generally English) than for native English-speakers. As in Gardner and Lambert's (1959) study of Canadian students, French students appear to exhibit elements of both integrative and instrumental motivations, in that perceived opportunities (PO), learning contexts (TC), and desire to identify and communicate with the new linguistic community (PA2, PA3, PE1) all received high ratings. However, our findings mainly point to an evolution between external and internal factors, with special attention to a relatively unexplored factor in foreign language research, namely, the social value of foreign language learning. More specifically, our findings suggest that the external and internal reasons for learning a foreign language become increasingly divergent as students progress from their first year of language classes into their second.

Factors that promote foreign language learning are twofold: a genuine interest in foreign languages as a field of study, and the perceived social 
value most probably associated with perceived opportunities. Factors that discourage foreign language learning are probably related to a decreasing perception of society's value for learning a foreign language as students progress in their studies. Faculties of foreign language studies might generate more positive attitudes in their students if they built their programs around the notion of foreign language learning as a social value important in the context of an increasingly globalized world, with both a cultural and a practical and utilitarian dimension. Given that there is an apparent evolution in students' beliefs and attitudes as they progress beyond the first year of their studies, further research should be conducted to try to tease out what exactly these perceptions are and how, qualitatively speaking, they evolve from year 1 to year 2 and year 3 . It would also be interesting to compare the evolution of such beliefs and attitudes with those of students who are not involved in foreign language learning. This could help determine the degree to which these types of beliefs and attitudes exist in other disciplines.

Teachers of English as a foreign language in France need to keep in mind that their students enter their classes with both instrumental and integrative motivations. As such, the communicative aspect of foreign language learning associated with cultural learning is key in ensuring direct relevance in professional settings, as well as facilitating cross-cultural understanding and communication. How teachers can better ensure oral practice of foreign languages as well as communication in contemporary contexts needs to be explored. Teachers should invite a dialogue that helps students position themselves in the role that they might play both professionally and humanistically as the need for a lingua franca becomes increasingly paramount, and as the need to respond to linguistic and cultural diversity within and beyond our borders increases. Conversely, teachers of foreign languages in North America, and in Canada in particular, need to keep in mind the danger of succumbing to the temptations of linguistic isolationism, as well as to the imperialist tendency to impose our own linguistic model on the rest of the world. The attacks of 9/11 remind us of the myth of the developed world as a fortress, be it linguistic, economic, or political, and thus recall of the importance of learning foreign languages in attempting to develop positive and reciprocal relationships with the rest of the world.

\section{Acknowledgments}

A version of this article was presented at the 12th World Congress on Comparative Education in Havana, Cuba, October 25-29, 2004.

The authors thank the following for facilitating access to foreign language departments and classes: Université du Var à Toulon, UFR de Lettres et de Sciences Humaines, Université de Provence à Aix, Département d'Etudes du Monde Anglophone, Université de Perpignan, UFR de Lettres, Langues et Sciences Humaines, Département de LEA, Université de Perpignan, UFR de Lettres, Langues et Sciences Humaines, Département de LLCE, Université Paris-Sorbonne, Paris IV, UFR de LEA. 
The authors also thank the Social Science and Humanities Research Council of Canada for funding much of the research on which this article is based.

\section{The Authors}

Nathalie Piquemal earned a doctorate in education and anthropology from the University of Alberta in 1999. She is an assistant professor in the Faculty of Education in the University of Manitoba. Her research interests include cross-cultural education, research ethics, and social contexts of foreign language learning.

Robert Renaud earned a doctorate in psychology from the University of Western Ontario in 2002. He currently teaches educational psychology, research methods, program evaluation, and advanced quantitative methods. His research interests include performance indicators, critical thinking, and quantitative methods.

\section{References}

Ashworth, M. (1985). Beyond methodology: Second language teaching and the community. Cambridge, UK: Cambridge University Press.

Beaud, S. (2004). Le bac est-il encore un passeport pour le futur? La Provence. 4 Avril.

Byrne, B.M. (2001). Structural equation modeling with AMOS: Basic concepts, applications, and programming. Mahwah, NJ: Erlbaum.

Calvet, L.J. (1999). Pour une écologie des langues du monde. Paris: Plon.

Demmert, W.G., Jr. (1993). Language, learning and national goals: A Native American view. The issues of language and culture: Proceedings of a symposium. Washington, CD: Center for Applied Linguistics.

Dörnyei, Z. (2003). Attitudes, orientations, and motivations in language learning: Advances in theory, research, and applications. Language Learning, 53(1), 3-32.

Fishbein, M., \& Ajzen, I. (1975). Belief, attitude, intention and behavior: An introduction to theory and research. Reading, MA: Addison-Wesley.

Gardner, R.C. (1985). Social psychology aspects of second language learning: The role of attitudes and motivation. London: Arnold.

Gardner, R.C., \& Lambert, W.E. (1959). Motivational variables in second language acquisition. Canadian Journal of Psychology, 13, 266-272.

Gardner, R.C., \& Lambert, W.E. (1972). Attitudes and motivations in second language learning. Rowley, MA: Newbury House.

Graham, C.R., \& Brown, C. (1996). The effects of acculturation on second language proficiency in a community with a two-way bilingual program. Bilingual Research Journal, 20, 235-260.

Goldin, M.G. (1987). Why Johnny can't acquire Spanish. Hispania, 70, 650-654.

Gumperz, J., \& Hymes, D. (Eds.). (1972). Directions in sociolinguistics. New York: Holt, Rinehart and Winston.

Hagège, C. (1996). Le français, histoire d'un combat. Paris: Editions Michel Hagège.

Horwitz, E.K. (1988). The beliefs about language learning of beginning university foreign language students. Modern Language Journal, 72, 283-293.

Horwitz, E.K. (1991). Language anxiety. From theory and research to classroom implications. Englewood Cliffs, NJ: Prentice Hall.

Hu, L.-T., \& Bentler, P.M. (1999). Cutoff criteria for fit indexes in covariance structure analysis: Conventional criteria versus new alternatives. Structural Equation Modeling: A Multidisciplinary Journal, 6, 1-55.

Hymes, D. (1972). Models of the interaction of language and social life. In J. Gumperz \& D. Hymes (Eds.), Directions in sociolinguistics. New York: Holt, Rinehart and Winston.

Jernigan, C.G. (2001). The role of beliefs, attributions, and perceived goal attainment in students' motivation. In G. Bräuer (Ed.), Pedagogy of language learning in higher education (pp. 23-45). Westport, CT: Ablex. 
Kamhi-Stein, L.D. (2003). Reading in two languages: How attitudes toward home language and beliefs about reading affect the behaviors of "underprepared" L2 college readers. TESOL Quarterly, 37, 35-71.

Kasuya, K. (2001). Discourses of linguistice dominance: A historical consideration of French language ideology. International Review of Education, 47, 235-251.

Kern, R.G. (1995). Students' beliefs and teachers' beliefs about language learning. Foreign Language Annals, 28, 71-92.

Lang, J. (2001, January 29). Minister of Education, France, Speech. (http://www/education.gouv.fr/discours/2001/dlangviv.htm.p. 10). www.education.gove.fr/thema/langue/langueb2.htm)

MacIntyre, P., \& Gardner, R. (1994). How does language anxiety affect second language learning? A reply to Sparks and Ganschow. Modern Language Journal, 79, 90-99.

Mantle-Bromley, C. (1995). Positive attitudes and realistic beliefs: Links to proficiency. Modern Language Journal, 79, 372-386.

Martin, I. (1990). Vocabulary acquisition in a content-based approach. Guidelines, 12(2), 1-11.

Masgoret, A.M., \& Gardner, R.C. (2003). Attitudes, motivation, and second language learning: A meta-analysis of studies conducted by Gardner and associates. Language Learning, 53(1), 167-207.

Miele, P. (1982). Suggestopedia: Easier learning the natural way. Sandy Spring, MD: Utopia Unlimited.

Norton, B., \& Toohey, K. (2001). Changing perspectives on good language learners. TESOL Quarterly, 35, 307-322.

Oxford, R.L. (1990). Language learning strategies: What every teacher should know. New York: Newbury House.

Pennycook, A. (1994). The cultural politics of English as an international language. London: Longman.

Rifkin, B. (2000). Revisiting beliefs about foreign language learning. Foreign Language Annals, $33,394-420$

Rogoff, B. (1994). Developing understanding of the idea of communities of learners. Mind, Culture and Activity, 1, 209-229.

Strevens, P. (1978). The nature of language teaching. In R.C. Richards (Ed.), Understanding second and foreign language learning: Issues and approaches (pp. 179-203). Rowley: Newbury House.

Turner, P.R. (1974). Why Johnny doesn't want to learn a foreign language. Modern Language Journal, 58, 155-196.

\section{Appendix}

Complete wording of items from the questionnaire

"Social-suggestive norms in foreign language learning"

Social Value

SV1 There are government policies which encourage the French to learn foreign languages

SV2 French people believe that learning foreign languages is just a normal part of life

SV3 French people are becoming more interested in learning a foreign language 
Perceived Opportunities

PO1 People who can use more than one language have more educational opportunities than those who do not

PO2 I often see job advertisements asking for people who speak more than one language

PO3 I need to learn a foreign language to get a good job

Taking Classes

TC1 For people learning a foreign language at a beginning level, foreign language classes are important

TC2 For people learning a foreign language at an intermediate level, foreign language classes are important

TC3 For people learning a foreign language at an advanced level, foreign language classes are important

Personal Attitudes

PA1 Foreign language learning is an interesting activity

PA2 It is important to learn a foreign language and culture together

PA3 I would like to learn a foreign language so that I can get to know its speakers better (BALLI)

Personal Experience

PE1 I often try to communicate with people who speak the language I am learning

PE2 I often read the newspaper in a foreign language 